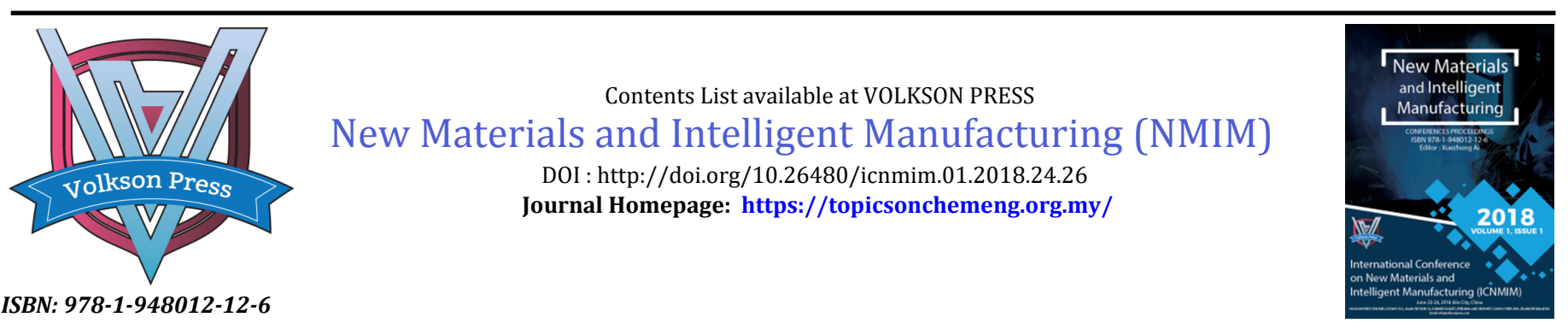

\title{
STUDIES ON SUZUKI COUPLING REACTIONS OF LARGE STERICALLY HINDERED SUBSTRATES
}

\author{
Jian Sun, Zhaohui Jin, Ning Xie, Hong Wang, Huajing Gao* \\ Institute of Petrochemical Technology, Jilin Institute of Chemical Technology, Chengde Street, Jilin, China. \\ *Corresponding Author Email: huajing_gao@163.com
}

This is an open access article distributed under the Creative Commons Attribution License, which permits unrestricted use, distribution, and reproduction in any medium, provided the original work is properly cited

\section{ARTICLE DETAILS $\quad$ ABSTRACT}

\section{Article History:}

Received 26 June 2018 Accepted 2 July 2018 Available online 1 August 2018

\begin{abstract}
Suzuki coupling reaction of 2-(Trifluormethoxy) phenylboronic acid with 2-bromo-1,3-dichloro-5-nitrobenzene were successfully conducted by using $\mathrm{Pd}_{2}(\mathrm{dba})_{3}$ as the catalyst and in satisfactory to good yields. The 4-(2(diphenylphosphino)phenyl) morpholine was the best ligand in this reaction. Biaryl amides 8t which gained much attention in the pharmaceutical industry because of using as ROR $\gamma$ t inhibitors could be synthesized using the product of Suzuki reaction $3 \mathrm{a}$ as the substrate after 2 steps. Higher yield of $8 \mathrm{t}$ could be got by using this method than the previous work.
\end{abstract}

\section{KEYWORDS}

Pd catalyst, Suzuki coupling reaction, hindered

\section{INTRODUCTION}

Palladium-catalyzed coupling reactions are becoming a valuable tool in the synthesis of carbon-carbon and carbon-heteratom bonds in modern chemistry [1-3]. These reactions are widely applied in pharmaceutical intermediates, polymer functional materials, pesticides, dyes and organic electroluminescent materials [4-12]. Particularly, Over $60 \%$ of the carboncarbon bond-forming processes in medicinal chemistry are now accomplished using the Suzuki cross-coupling reaction because of its low toxicity, high-efficiency good functional group tolerance and mild reaction conditions $[13,14]$. However, the low yields could be received when using large sterically hindered and macromolecule substrates in Suzuki coupling reaction. Recently, $N$-(2,6-dichloro-2'-(trifluoromethoxy)biphenyl-4-yl)2-(4-(ethylsulfonyl)phenyl)acetamide (8t), which synthesized by 2(trifluoromethoxy) phenylboronic acid (1a) and N-(4-bromo-3,5dichlorophenyl)-2-(4-(ethylsulfonyl)phenyl) acetamide (4t) was reported (see Figure. 1) [15]. Low yield ( 20\%) and the unobtainable substrate (4t) limited the application of $\mathbf{8 t}$ which was used as the ROR $\gamma$ t inhibitors.

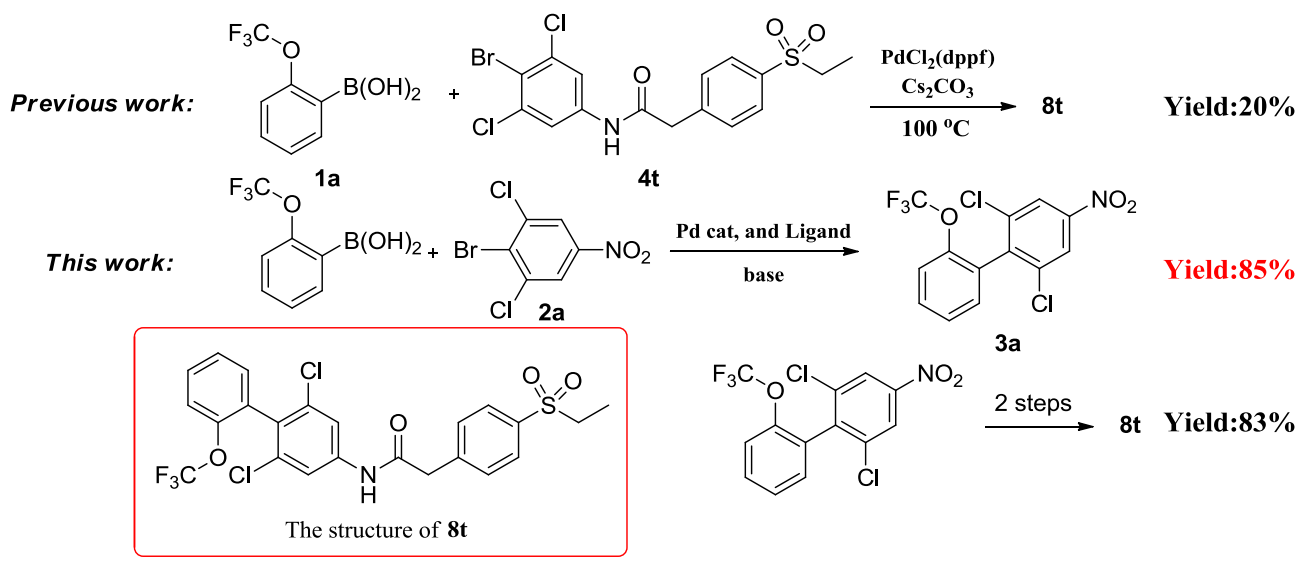

Figure 1: Pd-catalyzed Suzuki coupling reactions for synthesis compound 8t

Herein, we report the Suzuki coupling reaction of 2-(Trifluormethoxy) phenylboronic acid with 2-bromo-1,3-dichloro-5-nitrobenzene which were successfully conducted by using $\mathrm{Pd}_{2}(\mathrm{dba})_{3}$ as the catalyst and 4-(2(diphenylphosphino)phenyl)morpholine (L1) as a ligand to get the product 2,6-dichloro-4-nitro-2'-(trifluoromethoxy)-1,1'-biphenyl (3a) in satisfactory to good yields $[16,17]$. Based on $\mathbf{3 a}$ as the substrate, $8 \mathbf{t}$ could be received. Remarkable, higher yield (more than 70\%) could be got of $\mathbf{8 t}$ which proceed after 3steps by using this method (see Figure 1).

\section{RESULT AND DISCUSSION}

In the initial study, the reaction of $1 \mathrm{a}$ with $2 \mathrm{a}$ in the presence of $\mathrm{Pd}$ catalysts, ligands and base was selected as a model for the optimization of reaction conditions (Table 1 ). A series of palladium precatalysts, including $\mathrm{PdCl}_{2}, \mathrm{Pd}_{2}(\mathrm{dba})_{3}, \mathrm{Pd}(\mathrm{OAc})_{2}$, and $\mathrm{Pd}\left(\mathrm{PPh}_{3}\right)_{4}$ were initially tested in the tetrahydrofuran (THF) at $60^{\circ} \mathrm{C}$ by using triphenylphosphine $\left(\mathrm{PPh}_{3}\right)$ and potassium carbonate $\left(\mathrm{K}_{2} \mathrm{CO}_{3}\right)$ as a ligand and a base, respectively (entries 1-4). Among the palladium precatalysts tested, $\mathrm{Pd}_{2}(\mathrm{dba})_{3}$ exhibited a highest catalytic activity, affording the benzyl but-3-enoate $3 \mathrm{a}$ ) in $60 \%$ 
yield (entry 2). No reaction was observed when no ligand was added, suggesting that the ligand was necessary (entries 5). As expected, the use of sterically bulky $P$-ligands (L1, DPPF, DPPB) led to the occurrence of the desired product in $15-85 \%$ yields (entries $6-8$ ). The more sterically bulky $P$-bidentate ligand L1 proved to be the best ligand (entries 6). But, no reaction was observed when using dipyridyl as the $\mathrm{N}$-bidentate ligand (entries 9). We screened several base $\left(\mathrm{K}_{2} \mathrm{CO}_{3}, \mathrm{Cs}_{2} \mathrm{CO}_{3}\right.$, and $\left.\mathrm{NaOH}\right)$ to determine a suitable base (entries 6,10 , and 11). These results indicated that $\mathrm{K}_{2} \mathrm{CO}_{3}$ is the most suitable base for the reaction. The yield of $3 \mathrm{a}$ decreased to $66 \%$ when the reaction was performed under $50{ }^{\circ} \mathrm{C}$ (entries 12). Further studies revealed that the similar yield of product $3 \mathrm{a}$ was obtained when the reaction temperature was enhanced to $70{ }^{\circ} \mathrm{C}$ or the reaction time up to $1.5 \mathrm{~h}$, respectively (entries 13 and 14). A slightly decreased yield was obtained when the reaction was performed under 0.5 $\mathrm{h}$ (entries 15)

Table 1: Reaction condition screening of Suzuki ${ }^{a}$<smiles>FC(F)(F)CCCCCCCCCOc1ccccc1OC(F)(F)F</smiles>
1a<smiles>O=[N+]([O-])c1cc(Cl)c(Br)c(Cl)c1</smiles>

2a<smiles>O=[N+]([O-])c1cc(Cl)c(-c2ccccc2OC(F)(F)F)c(Cl)c1</smiles>

3a
L1:

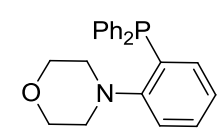

\begin{tabular}{|lllll|}
\hline entry & catalyst & ligand & base & yield $(\%)^{b}$ \\
\hline 1 & $\mathrm{PdCl}_{2}$ & $\mathrm{PPh}_{3}$ & $\mathrm{~K}_{2} \mathrm{CO}_{3}$ & 7 \\
2 & $\mathrm{Pd}_{2}(\mathrm{dba})_{3}$ & $\mathrm{PPh}_{3}$ & $\mathrm{~K}_{2} \mathrm{CO}_{3}$ & 60 \\
3 & $\mathrm{Pd}_{2}(\mathrm{OAc})_{2}$ & $\mathrm{PPh}_{3}$ & $\mathrm{~K}_{2} \mathrm{CO}_{3}$ & 18 \\
4 & $\mathrm{Pd}\left(\mathrm{PPh}_{3}\right)_{4}$ & - & $\mathrm{K}_{2} \mathrm{CO}_{3}$ & 52 \\
5 & $\mathrm{Pd}_{2}(\mathrm{dba})_{3}$ & - & $\mathrm{K}_{2} \mathrm{CO}_{3}$ & 0 \\
6 & $\mathrm{Pd}_{2}(\mathrm{dba})_{3}$ & $\mathrm{~L} 1$ & $\mathrm{~K}_{2} \mathrm{CO}_{3}$ & 85 \\
7 & $\mathrm{Pd}_{2}(\mathrm{dba})_{3}$ & $\mathrm{DPPF}$ & $\mathrm{K}_{2} \mathrm{CO}_{3}$ & 20 \\
8 & $\mathrm{Pd}_{2}(\mathrm{dba})_{3}$ & $\mathrm{DPPB}$ & $\mathrm{K}_{2} \mathrm{CO}_{3}$ & 15 \\
9 & $\mathrm{Pd}_{2}(\mathrm{dba})_{3}$ & dipyridyl & $\mathrm{K}_{2} \mathrm{CO}_{3}$ & 0 \\
10 & $\mathrm{Pd}_{2}(\mathrm{dba})_{3}$ & $\mathrm{~L} 1$ & $\mathrm{Cs}_{2} \mathrm{CO}_{3}$ & 71 \\
11 & $\mathrm{Pd}_{2}(\mathrm{dba})_{3}$ & $\mathrm{~L} 1$ & $\mathrm{NaOH}_{3}$ & 50 \\
$12^{c}$ & $\mathrm{Pd}_{2}(\mathrm{dba})_{3}$ & $\mathrm{~L} 1$ & $\mathrm{~K}_{2} \mathrm{CO}_{3}$ & 66 \\
$13^{d}$ & $\mathrm{Pd}_{2}(\mathrm{dba})_{3}$ & $\mathrm{~L} 1$ & $\mathrm{~K}_{2} \mathrm{CO}_{3}$ & 84 \\
$14^{e}$ & $\mathrm{Pd}_{2}(\mathrm{dba})_{3}$ & $\mathrm{~L} 1$ & $\mathrm{~K}_{2} \mathrm{CO}_{3}$ & 85 \\
$15^{f}$ & $\mathrm{Pd}_{2}(\mathrm{dba})_{3}$ & $\mathrm{~L} 1$ & $\mathrm{~K}_{2} \mathrm{CO}_{3}$ & 80 \\
\hline
\end{tabular}

${ }^{a}$ Reaction conditions: (2-(trifluoromethoxy) phenyl)boronic acid $0.5 \mathrm{mmol}, 2$-bromo-1,3-dichloro-5-nitrobenzene $0.5 \mathrm{mmol}$, ligand (10 mol\%), Pd catalyst ( $5 \mathrm{~mol} \%$ ), base (2 equiv), THF ( $5 \mathrm{~mL}$ ) at $60^{\circ} \mathrm{C}$ for $1 \mathrm{~h} . ~^{b}$ Isolated yield. ${ }^{c}$ the reaction was performed for $50{ }^{\circ} \mathrm{C} .{ }^{d}$ The reaction was performed at $70{ }^{\circ} \mathrm{C} .{ }^{e} \mathrm{The}$ reaction was performed for $1.5 \mathrm{~h}$. ${ }^{\mathrm{T}}$ The reaction was performed for $0.5 \mathrm{~h}$.

\section{APPLICATION OF THE COMPOUND 3a}

Biaryl amides $8 \mathrm{t}$ has gained much attention in the pharmaceutical industry because of using as ROR $\gamma$ t inhibitors. Compound 3a was further transformed into 2,6-dichloro-2'-(trifluoromethoxy)-[1,1'-biphenyl]-4amine (4a) in the presence of $0.5 \mathrm{MPa} \mathrm{H}_{2}$ by gold nanopore (AuNPore) as a catalyst under room temperature for $2 \mathrm{~h}$ in $87 \%$ yield [18]. Then, acylation reaction was generated between $4 \mathrm{a}$ and (2-(4(ethylsulfonyl)phenyl)acetyl)oxonium in the presence of $\mathrm{N}-(3-$ dimethylaminopropyl)- $N$ '-ethylcarbodiimide hydrochloride (EDC) and 1Hydroxybenzotriazole (HOBt) in 95\% yield (see Figure. 2). The total yield of $8 \mathrm{t}$ from $3 \mathrm{a}$ was $83 \%$, so this method is better than the previous work.

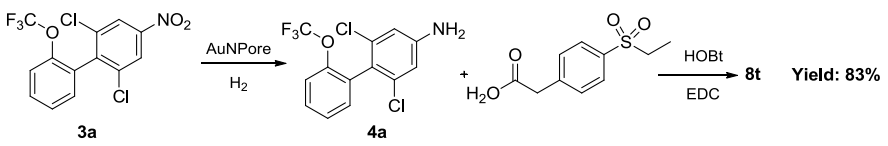

Figure 2: The synthetic procedure of compound $8 \mathrm{t}$

\section{CONCLUSIONS}

In summary, we developed a novel method for Suzuki coupling of large sterically hindered and macromolecule substrates in a good yield. Notably, this transformation offers a general process for converting the product $3 \mathrm{a}$ of the Suzuki reaction into potentially useful compound $\mathbf{8 t}$ in a excellent yield which higher than the previous work. Further reactions and mechanistic studies of $\mathbf{L} \mathbf{1}$ are underway in our laboratory and will be reported in due course.

\section{REFERENCES}

[1] Mejere, A. de., Diederich, F. 2004. Metal-catalysed cross-coupling reactions. Germany, Weinheim.
[2] Nicolaou, K.C., Bulger, P.G., Sarlah, D. 2005. Palladium-catalyzed crosscoupling reactions in total synthesis. Angewandte Chemie International Edition, 44, 4442-4489. doi: 10.1002/anie.200500368.

[3] Negishi, E. 2007. Transition metal-catalyzed organometallic reactions that have revolutionized organic synthesis. Bulletin of the Chemical Society of Japan, 80, 233-257. doi:10.1246/bcsj.80.233.

[4] Wolfe, J.P., Buchwald, S.L. 1999. A Highly Active Catalyst for the RoomTemperature Amination and Suzuki Coupling of Aryl Chlorides. Angewandte Chemie International Edition, 38 (16), 2413-2416.

[5] Zhang, W., Chen, H.T., Lu, Y., Nagashima, T. 2004. A highly efficient microwave-assisted Suzuki coupling reaction of aryl perfluorooctylsulfonates with boronic acids. Organic Letters, 6 (9), 14731476. doi: $10.1021 / 010496428$.

[6] Bahadir, M., Pieper, A., Vogt, R., Wichmann, H., Grunenberg, J., Hopf, H. 2003. Isomer specific synthesis using the Suzuki-coupling. Polychlorinated terphenyls as standards for environmental analysis. Chemosphere, 50 (9), $1151-1156$

[7] Blaser, H.U., Indolese, A., Naud, F., Nettekoven, U., Schnyder, A. 2004. Industrial R\&D on catalytic C-C and C-N coupling reactions: a personal accounton goals, approaches and results. Advanced Synthesis \& Catalysis, 346, 1583-1598. doi: 10.1002/adsc.200404156.

[8] Muehlebach, M., Boeger, M., Cederbaum, F., Cornes, D., Friedmann, A.A. Glock, J., Niderman, T., Stoller, A., Wagner, T. 2009. Aryldiones incorporating a $[1,4,5]$ oxadiazepane ring. Part I: discovery of the novel cereal herbicide pinoxaden. Bioorganic \& Medicinal Chemistry, 17, 42414256. doi: 10.1016/j.bmc.2008.12.062.

[9] Muehlebach, M., Cederbaum, F., Cornes, D., Friedmann, A.A., Glock, J., Hall, G., Indolese, A.F., Kloer, D.P., Goupil, G.L., Maetzke, T., Meier, H., Schneider, R., Stoller, A., Szczepanski, H., Wendeborn, S., Widmer, H. 2011. Aryldiones incorporating a $[1,4,5]$ oxadiazepanering. Part 2: chemistry and biology of the cereal herbicide pinoxaden. Pest Management Science, 67 (12), 1499-1521. doi: 10.1002/ps.2204. 
[10] An, Z.W., Catellani, M., Chiusoli, G.P. 1990. A new palladium-catalyzed synthesis of indoxyl derivatives. Journal of Organometallic Chemistry, 397, C31-C32.

[11] Wang, Y., Deng, X., Liu, Y., Ni, M., Liu, M., Tan, H., Li, X., Zhu, W., Cao, Y. 2011. White emission from dinuclear cyclometalated platinum (II) complex in single-emitting layer PLEDs. Tetrahedron, 67, 2118-2124. doi: 10.1016/j.tet.2011.01.042.

[12] Wang, Y., Liu, Y., Luo, J., Qi, H., Li, X., Nin, M., Liu, M., Shi, D., Zhu, W., Cao, Y. 2011. Metallomesogens based on platinum (II) complexes: synthesis, luminescence and polarized emission. Dalton Transactions, 40, 50465051. doi: 10.1039/c0dt01515f.

[13] He, Z., Song, F., Sun, H., Huang, Y. 2018. Transition-metal-free Suzukitype cross-coupling reaction of benzyl halides and boronic acids via 1,2metalate shift. Journal of the American Chemical Society, 140, 2693-2699. doi: 10.1021/jacs.8b00380.

[14] Schneider, N., Lowe, D.M., Sayle, R.A., Tarselli, M.A., Landrum, G.A. 2016. Big data from pharmaceutical patents : a computational analysis of medicinal chemists' bread and butter. Journal of Medicinal Chemistry, 59, 4385-4402. doi: 10.1021/acs.jmedchem.6b00153.

[15] Wang, Y., Cai, W., Cheng, Y., Yang, T., Liu, Q., Zhang, G., Meng, Q., Han, F., Huang, Y., Zhou, L., Xiang, Z., Zhao, Y.G., Xu, Y., Cheng, Z., Lu, S., Wu, Q., Xiang, J.N., Elliott, J.D., Leung, S., Ren, F., Lin, X. 2015. Discovery of biaryl amides as potent, orally bioavailable, and CNS penetrant ROR $\gamma \mathrm{t}$ Inhibitors. ACS Medicinal Chemistry Letters, 6, 787-792. doi: 10.1021/acsmedchemlett.5b00122.

[16] Dai, Y., Liu, H., Feng, X., Bao, M. 2011. Preparation and application of new $\mathrm{P}, \mathrm{N}$-ligands for palladium-catalyzed $\mathrm{C}-\mathrm{N}$ bond coupling reaction. Chinese Journal of Catalysis, 32, 1617-1623. doi: 10.3724/SP.J.1088.2011.10617.

[17] Zou, T., Feng, X., Liu, H., Yu, X., Yamamoto, Y., Bao, M. 2013. Efficient palladium-catalyzed cyanation of aryl/heteroaryl bromides with $\mathrm{K}_{4}\left[\mathrm{Fe}(\mathrm{CN})_{6}\right]$ in $\mathrm{t}-\mathrm{BuOH}-\mathrm{H}_{2} \mathrm{O}$ using tris(2-morpholinophenyl)phosphine as a ligand. RSC Advances, 3, 20379-20384. doi: 10.1039/c3ra43279c.

[18] Takale, B.S., Bao, M., Yamamoto, Y. 2014. Gold nanoparticle (AuNPs) and gold nanopore (AuNPore) catalysts in organic synthesis. Organic \& Biomolecular Chemistry, 12, 2005-2027. doi :10.1039/c3ob42207k.

\section{APPENDIXES}

Representative experimental procedure for the Suzuki coupling reaction
An oven-dried reaction tube $(25 \mathrm{~mL})$, fitted with magnetic stirrer, was charged with $\mathrm{Pd}_{2}(\mathrm{dba})_{3}(22.9 \mathrm{mg}, 0.025 \mathrm{mmol}), \mathrm{K}_{2} \mathrm{CO}_{3}(13.82 \mathrm{mg}, 1.0$ mmol), ligand $\mathbf{L 1}(17.35 \quad \mathrm{mg}, \quad 0.05 \quad \mathrm{mmol}), \quad 2$ (Trifluormethoxy)phenylboronic acid (95 $\mathrm{mg}, 0.5 \mathrm{mmol}$ ) and 2-bromo1,3-dichloro-5-nitrobenzene $(135.5 \mathrm{mg}, 0.5 \mathrm{mmol})$. The tube was evacuated and purged with nitrogen for three times. Then, freshly distilled THF ( $5 \mathrm{~mL})$ was added. The reaction mixture was heated to $60{ }^{\circ} \mathrm{C}$ for $1 \mathrm{~h}$. After the reaction completed, the resultant mixture was evaporated in a vacuum to give the crude product, which was then purified via chromatography (eluent: ethyl acetate/petroleum ether $=1: 20$ ) to afford product $3 \mathbf{a}$ as a yellow solid.

\section{Synthetic procedure for the compound $8 \mathrm{t}$}

The first step: a $25 \mathrm{~mL}$ oven dried autoclave vessel containing a stir bar was charged with $3 \mathrm{a}$ ( $175.5 \mathrm{mg}, 0.5 \mathrm{mmol}$ ) and AuNPore (5.0 mg, $5 \mathrm{~mol} \%$ ). The autoclave was evacuated and purged with nitrogen for three times. Then, triethylamine $(5 \mathrm{~mL})$ and $\mathrm{H}_{2}(1.0 \mathrm{MPa})$ were added. The reaction mixture was stirred at room temperature for $2 \mathrm{~h}$. Then the remaining $\mathrm{H}_{2}$ was vented slowly. The resultant mixture was evaporated in vacuo to give the crude product, which was then purified via silica gel chromatography (eluent: ethyl acetate/petroleum ether $=1: 2$ ) to afford 4a as light yellow oil.

The second step: An oven-dried reaction tube $(25 \mathrm{~mL})$, fitted with magnetic stirrer, was charged with 4 a $(160.5 \mathrm{mg}, 0.5 \mathrm{mmol})$, (2-(4(ethylsulfonyl)phenyl)acetyl)oxonium (114.0 mg, $0.5 \mathrm{mmol}$ ), HOBt (101.3 $\mathrm{mg}, 0.75 \mathrm{mmol}$ ) and EDC (116.4 mg, $0.75 \mathrm{mmol})$. The tube was evacuated and purged with nitrogen for three times. Then, freshly distilled dichloromethane $(5 \mathrm{~mL})$ was added. The reaction mixture was stirred at room temperature for $1 \mathrm{~h}$.. After the reaction completed, the resultant mixture was evaporated in a vacuum to give the crude product, which was then purified via chromatography (eluent: ethyl acetate/petroleum ether $=1: 2$ ) to afford product $8 \mathbf{t}$ as a yellow solid.

\section{${ }^{1}$ H NMR of 8t}

${ }^{1} \mathrm{H}$ NMR $\left(400 \mathrm{MHz}, \mathrm{CDCl}_{3}\right)$ spectra of the products 8t: $\delta$ ppm $7.89(\mathrm{~d}, J=$ $8.0 \mathrm{~Hz}, 2 \mathrm{H}), 7.67(\mathrm{~s}, 2 \mathrm{H}), 7.55(\mathrm{~d}, J=8.0 \mathrm{~Hz}, 2 \mathrm{H}), 7.48(\mathrm{~m}, 1 \mathrm{H}), 7.37(\mathrm{~m}, 2 \mathrm{H})$, $7.25(\mathrm{~m}, 2 \mathrm{H}), 3.84(\mathrm{~s}, 2 \mathrm{H}), 3.15(\mathrm{q}, J=7.6,7.2 \mathrm{~Hz}, 2 \mathrm{H}), 1.31(\mathrm{t}, J=7.2 \mathrm{~Hz}$, $3 \mathrm{H})$.

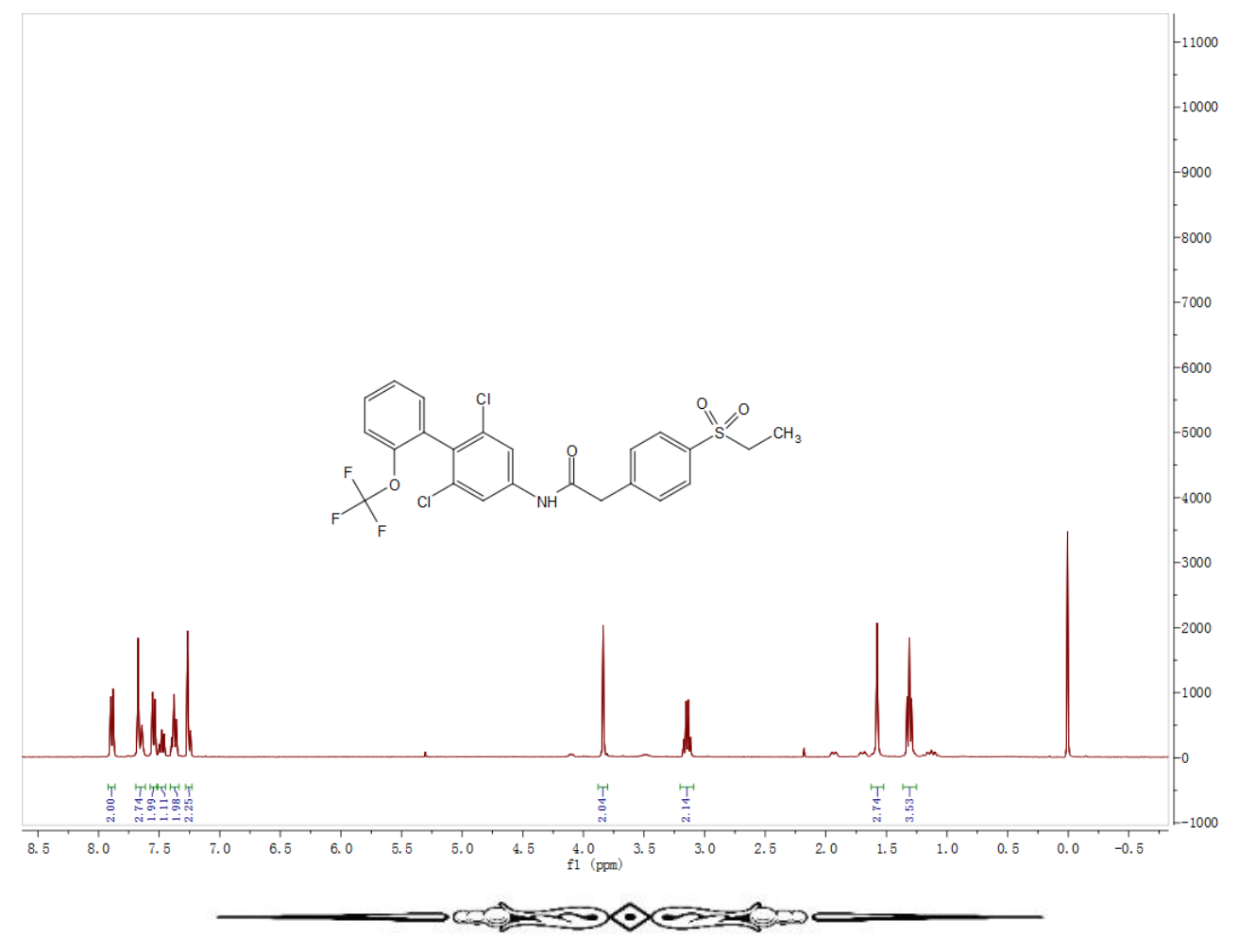

